Fecha de recepción: abril 2020

Fecha de aceptación: mayo 2020

Versión final: junio 2020

\section{Bauhaus en perspectiva: la evolución y persistencia de una idea. Una mirada al espacio doméstico moderno}

Fernanda M. Aguirre Bermeo ${ }^{(1)}$

Resumen: La Bauhaus constituye la más importante -si no, la más conocida- Escuela de diseño y arte del s. XX. Pero la historia de la Escuela es tan compleja como las personalidades en su escena. Mirar su evolución da cuenta de ello.

A pesar del relativamente corto tiempo de existencia la Escuela logró aportaciones importantes en el ámbito del diseño, el arte y la arquitectura a la vez que formó mentes y criterios de inevitable reverberación.

De entre todas sus contribuciones se propone enfocar la construcción del espacio habitable. Así, el trabajo a continuación procura una mirada hacia la evolución del pensamiento alrededor del espacio doméstico. Para ello usa como base el hilo histórico y a través de él se establecen conexiones entre el pensamiento de cada momento de la Escuela y los hechos arquitectónicos producidos dentro y fuera de ella. A riesgo de parecer meras coincidencias entre aquellos ya sea porque la sociedad sucumbía ante la industrialización obsesiva y sus consecuentes dinámicas y por tanto demandaba una única dirección de pensamiento o porque podrían suponerse simplemente como hechos aislados la construcción del punto de vista que aquí se sugiere, se propone sumar un valor: la persistencia; siendo aquella la capacidad inherente en la experimentación y en la conformación -en este caso- del espacio doméstico. Se intentará, por tanto, tocar una de las dimensiones de la Bauhaus donde el diseño, el arte y la arquitectura promulgados aparecen fuertemente fusionados: en el espacio doméstico.

Se podrá ver entonces que el proceso de unificar arte e industria -luego, arte y artista, arte y sociedad-arrancó con un ideario que evolucionaría y llegaría a convertirse en una persistencia inherente en el criterio de la forma moderna: la construcción total del espacio sin que ningún elemento quede sin definir, entendiéndose así que la escala no es más que una dimensión. A este punto puede llegar a afirmarse que la verdadera experiencia de la Escuela se retrata en sus alumnos y además en los arquitectos quienes a pesar de no haber pasado por la Escuela ejercieron la arquitectura a través de su influencia. Ellos y sus obras son quizá los verdaderos protagonistas y quienes dan cuenta de que más allá de la Institución, los ideales persistieron en el espíritu del arte total unido a la arquitectura. El diseño del espacio habitable quizá no podría haberse palpado si no fuese a través de sus aportes.

Palabras clave: espacio doméstico - espacio habitable - arte y tecnología - arte y arquitectura - vivienda Bauhaus.

[Resúmenes en inglés y portugués en las páginas 127-129] 
${ }^{(1)}$ Arquitecta (Universidad de Cuenca). Máster en Teoría y Práctica del Proyecto de Arquitectura y Doctora en Proyectos Arquitectónicos (Universidad Politécnica de Cataluña). Investigadora en el grupo FORM+ de la ETSAB Universidad Politécnica de Cataluña, con proyectos enfocados en el estudio de la arquitectura moderna en América Latina. Docente en la Facultad de Diseño, Arte y Arquitectura de la Universidad del Azuay, Cuenca.

\section{Introducción. La mirada en perspectiva y la necesidad del escorzo}

Re-ver la Escuela de la Bauhaus en su centésimo aniversario evoca una mirada en perspectiva. Sin duda, la aportación de la Escuela tiene muchas dimensiones que han sido $-\mathrm{y}$ siguen siendo- objeto de estudio desde hace varias décadas y han posibilitado establecerse como insumos de conocimiento y como nuevos hilos de investigación. Es claro que, todo depende de cómo se lo mire.

La mirada en perspectiva ayuda a construir una propia representación de las cosas. Siempre que se fije un punto inicial, es decir, un punto de vista, se definirán características y valores. Es en suma, el paso hacia la contemplación de una realidad compleja.

Aludiendo a la Perspectiva como técnica de dibujo, imaginemos que tenemos en frente un cuadrado. Podríamos asegurar quizá que se trata de un plano bidimensional pero no sabremos si se trata de un plano en vista frontal, o tal vez lateral, tal vez posterior o superior. En cambio, cuando definimos un punto de vista, podemos ilustrar la dimensión de la figura. Podemos, en fin, evocar hacia la complejidad y ver en ella el "grosor" de las cosas. Se ha de confesar que aquella preocupación no es del todo novedosa. En cuanto al mirar en perspectiva existen muchos personajes -artistas, arquitectos, investigadores, que han optado por tal método. Por mencionar un ejemplo, hacia los años 20, Aleksandr Ródchenko (San Petersburgo, 1891 - Moscú, 1956) -escultor, pintor, diseñador gráfico y fotógrafo ruso- decía sobre sí mismo, hablando en tercera persona:

Entre sus manos la Leica negra de níquel y cristal se pone con amor al trabajo. Mostrará este mundo. Mostrará el mundo habitual y cotidiano. Bajo un nuevo ángulo. Hará propaganda con la fotografía. Propaganda de todo lo nuevo, joven y original (Ródchenko, 2001, p. 59).

En las fotografías de Ródchenko [Figura 1, Figura 2] no es difícil darse cuenta de la búsqueda de posibilidades abiertas a la fotografía asumiendo con ímpetu que ésta es libre de la imitación de las técnicas de la pintura, de grabados y otras artes. Justamente, el punto de vista adquiere valor imprescindible para dar cuenta de aquel nuevo mundo bajo un nuevo ángulo: los escorzos acentuados, la captura del movimiento, composiciones con riqueza de formas y tramas intrincadas. Son, según un análisis del profesor J. Antonio Cortés: “[...] rasgos de modernidad: la oblicuidad, que pone en cuestión la vertical gravitatoria $y$, por tanto, niega el equilibrio horizontal-vertical, y la seriación ilimitada hacia lo alto" (Cortés, 2016, p. 30). 

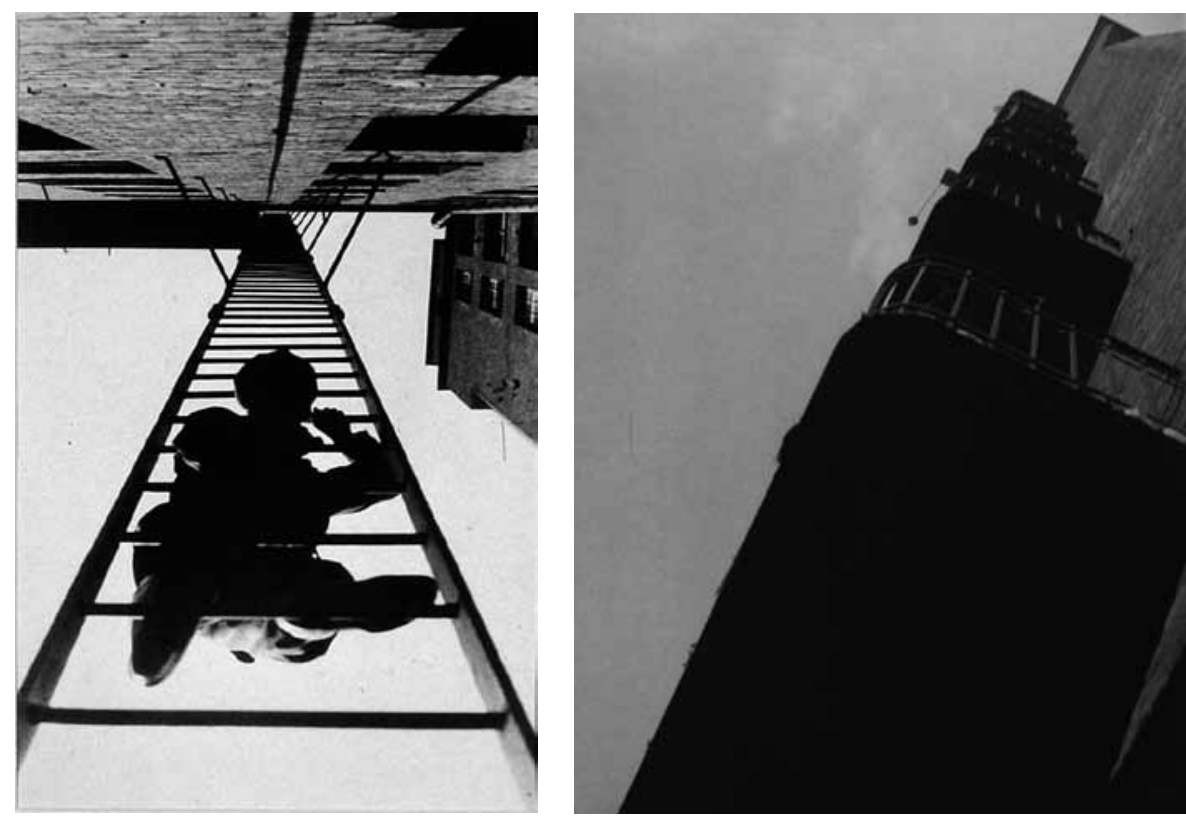

Figura 1 (izquierda). Firescape, 1925. Figura 2 (derecha). Balcones de la serie "El edifico de la calle Miasnitskaia”, 1925.

Sin ánimo de ahondar en aquello, advertir simplemente al lector que el punto de vista que descubrirá a continuación es una construcción, fruto -quizá- de preocupaciones propias por indagar en maneras de analizar y comprender un tópico de antiquísimo y aún constante motivo de estudio: la vivienda.

El bien sabido espíritu experimental en la Escuela Bauhaus recae en el diseño del espacio doméstico con especial potencia. El debate de décadas pasadas ente el tipo y la individualidad intentarán subsanarse sin perder de vista que los procesos de industrialización serán necesarios para el "desarrollo" de las sociedades.

Entre tantas investigaciones críticas e historiográficas alrededor de este tema y de la Bauhaus quizá la de mayor alcance es la posición de Kenneth Frampton al hablar de la Bauhaus como "la evolución de una idea". No obstante, en consecuencia a la construcción del punto de vista que aquí se sugiere, se propone sumar un valor: la persistencia; siendo aquella la capacidad inherente en la experimentación y en la conformación -en este casodel espacio doméstico. Se intentará, por tanto, tocar una de las dimensiones de la Bauhaus donde el diseño, el arte y la arquitectura promulgados aparecen fuertemente fusionados: en el espacio doméstico. 


\section{Puntos focales en el hilo histórico del arte, la industria, la vivienda y la ciudad}

\section{El taller de la industrialización}

Hacia finales del s. XIX el capitalismo industrial y sus imposiciones mecanizadas pasaba factura a los valores del arte poniendo en cuestionamiento el significado de la artesanía en el diseño. Alemania se posicionaba como la nación más competitiva en el ámbito europeo. En 1898 Karl Schmidt, experto ebanista fue de los pioneros en estandarizar objetos y procesos con el principal interés de reducir costos y avanzar hacia la producción mecánica empleando siempre a arquitectos y artistas modernos como diseñadores.

La academia no tardaría en alzar la voz. Por un lado, Hans Poelzig y Peter Beherens en 1903, en Breslau (actual Wrockaw, Polonia) fundan la Escuela Alemana de Artes y Oficios (Kunstgewerbeschule) y por otro, una segunda Escuela Alemana de Artes y Oficios en Weimar fundada en 1906 bajo la dirección de Henry Van de Velde.

Pero la obstinación hacia la industrialización continuaba y en 1907 se funda el Deutsche Werkbund. Esta asociación de artistas e industriales se dedicó -en principio- a mejorar la educación artesanal pero que dada su heterogeneidad no estaban totalmente de acuerdo con el ideal de uno de sus fundadores, Hermann Muthesius: un ideal de organización monopolizada del capital. Y es que tal objetivo estuvo amagado por el intento de mejorar la calidad de los productos industriales alemanes dándole al artista un rol económico en la rueda capitalista al mismo tiempo que ofrecía al consumidor un artículo diseñado por un artista a manera de compensación del vínculo artesanal perdido.

Años más tarde, aconteció un importante debate cuestionado fuertemente por Henry Van de Velde -y en acto seguido, apoyado por Peter Beherens e incluso Walter Gropius- por la clara sazón oportunista. Hermann Muthesius en 1914, frente a la asamblea del Deutsche Werkbund, ante la preocupación por la división entre norma y forma, entre el tipo y la individualidad, sostenía que la arquitectura y el diseño industrial sólo podían recobrar su significado mediante el desarrollo y perfeccionamiento de los tipos. A ello, la necesidad de fabricar productos de alto nivel que pudieran venderse fácilmente en el mercado mundial con la condición previa de la existencia de grandes empresas comerciales con un "firme sentido de gran gusto". El apoyo a Van de Velde causó la inmediata supresión del programa de Muthesius.

\section{El arte en la industrialización: posibilidad o contradicción}

En 1919, Walter Gropius elaboró la introducción a una muestra de trabajos visionarios protagonizada por algunos de los miembros del Comité de Trabajo para el Arte ${ }^{1}$, colectivo que dirigía junto a Adolf Behne y Bruno Taut desde un año atrás. Esta organización montada por Bruno Taut y Adolf Behne compartía la idea de que el arte y pueblo debían constituir una unidad: "El arte no debe ser nunca más el placer de unos pocos, sino la vida 
y la felicidad de las masas. El objetivo es lograr la alianza de las artes bajo las alas de una gran arquitectura" (Frampton, 2001, p. 119).

Este texto de Gropius constituyó además el primer borrador para la Escuela Bauhaus de Weimar:

Deseemos juntos, pensemos juntos, creemos juntos la nueva idea de la arquitectura. Pintores y escultores, abríos un camino a través de los obstáculos que os separan de la arquitectura y convertíos en compañeros constructores, compañeros de lucha por el objetivo final del arte: la concepción creativa de la catedral del futuro, que debe englobar de nuevo, en una forma total y única, la arquitectura, la escultura y la pintura (Frampton, 2001, p. 120).

Su enunciado resultaba contradictorio a la inquebrantable dinámica industrial y demostraba el aún latente conflicto que los miembros de Deutsche Werkbund sintieron años antes. Negar los procesos de industrialización resultaba un error pero igualmente equívoco era relegar al arte hacia la pintoresca artesanía o peor aún, hacia la manufactura elitista. Aún así, sus palabras representaban un germen hacia la reformulación de las Artes Aplicadas. El espíritu Bauhaus es en este sentido un puñado de reflexiones y contradicciones cocidas a fuego lento. Pero el recorrido apenas comenzaba.

\section{La vivienda en la industrialización}

Llegados a este punto se hace necesario un quiebre en este relato que ponga en advertencia lo que sucedía en el ámbito de la ciudad como consecuencia de la industria creciente. Porque los ideales de la "forma total y única" de Gropius incluían a la arquitectura que si bien -según el teórico que lo enuncie- es una práctica artística, sus ámbitos de acción difieren de aquellos de los objetos. Es decir, resulta evidente que la aparición de la industria trajo consigo la separación entre vivienda y trabajo y que la ciudad, que es el campo de acción de la arquitectura, se vio de pronto transformada.

De manera general, se puede decir que la ciudad tradicional, compacta, homogénea se vio invadida por las dinámicas de industrialización y sus estructuras desproporcionadas, por los consecuentes torrentes migratorios abrumantes y en efecto, el crecimiento de la ciudad y la transformación de su paisaje urbano ${ }^{2}$. Además, la periferia resultaba una oportunidad para la explotación desmesurada del suelo y con ello dar paso a procesos especulativos. Por supuesto, las condiciones de habitabilidad eran precarias, incluso inexistentes. Es éste el escenario en el que se desenvolverá el Movimiento Moderno.

Las reformulaciones urbanísticas a través de los modelos de ciudad jardín y los de la ciudad concentrada abrían nuevos paradigmas de la vivienda: desde la vivienda como célula autónoma pero con organización colectiva, a la edificación en altura, en línea o en asociación con otros edificios. Se comprende entonces que el espacio doméstico entra en un estado de adaptación, de nueva organización definida por la necesidad del uso de dimensiones básicas -o mínimas- en terrenos periféricos o en intersticios de ciudad. La vivienda se había de engranar a la rueda de la industrialización. Sus procesos habrían de 

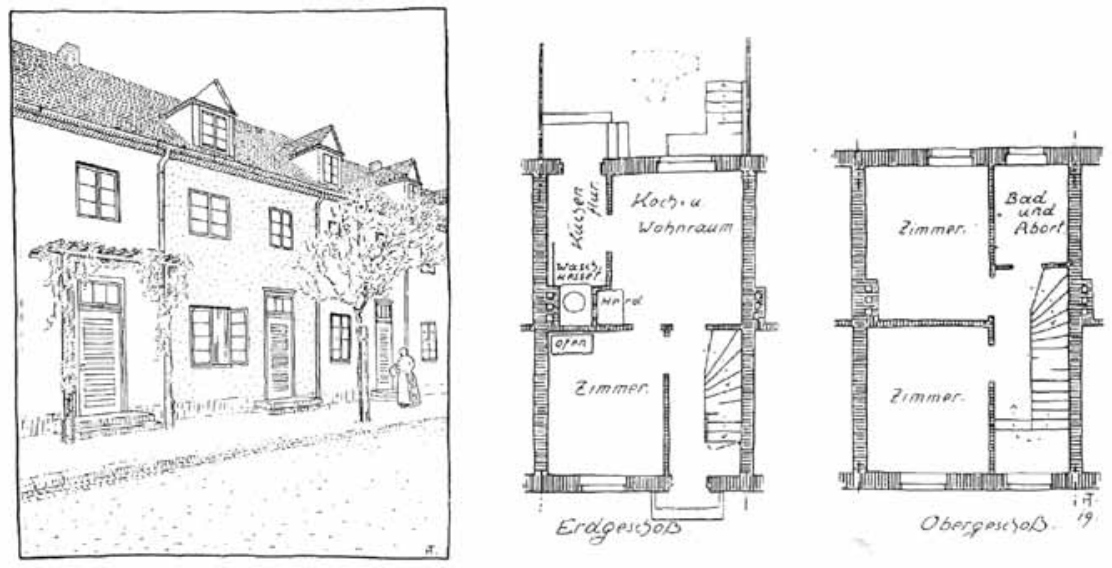

Figura 3. Vivienda para un trabajador. Heinrich Tessenow, 1908

ser igual de normados, modulados y asequibles al ahorro capital. Esta noción flotaba entre varios destacados arquitectos de la época. Heinrich Tessenow en su proyecto de viviendas en hilera en Rähnitz, Dresden (1919) busca, al igual que en sus dibujos, organizar espacios esenciales y precisos; muestran un medio término entre modernidad y tradición, entre lo industrial y lo artesanal [Figura 3].

La búsqueda de un nuevo arquetipo es quizá muestra indudable de la necesidad de organización y producción en masa al tiempo de una reflexión entorno a las necesidades humanas. Estudiosos de la obra de Tessenow afirman que su obra difícilmente encaja en algún movimiento del s. XX porque aunque esté asociado al tiempo de los nuevos paradigmas de la vivienda, su interés radicaba mucho más en el ser humano y los aspectos sociales de los edificios que en la creación misma de un nuevo estilo ${ }^{3}$.

\section{Bauhaus, una escuela taller y academia de artes}

Arte, artista, artesano, vivienda, habitabilidad, industria, ciudad, son tópicos importantes de la época que no fueron indiferentes en Bauhaus. Aunque no puede decirse que la Escuela abordó todos aquellos, lo que interesa mostrar es que a pesar de algunas divergencias de sus miembros, la Escuela posibilitó la indagación constante y la experimentación. Además porque el elevado grado de importancia que alcanzó en su contexto influyó en el quehacer de talentosos artistas y arquitectos. 


\section{Experimentación expresionista}

Bauhaus nace -al igual que varias Escuelas o Academias de Arte ${ }^{4}$ - en el intento de acercar la distancia entre arte y la producción industrial. Se posiciona como una institución mixta: una Academia de Bellas Artes y una Escuela Taller de aprendizaje. El ideal de su fundador se resume en: "La recuperación de los métodos artesanales en la actividad constructiva, en

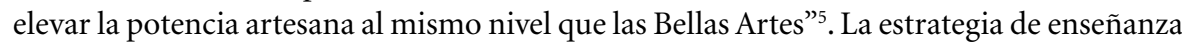
era imprescindible: los maestros - profesores-formaban a aprendices -alumnos- a través de un sistema combinado de Talleres dirigidos, al mismo tiempo, por Maestros de Taller y por Maestros de Forma. Los primeros se encargaban de la enseñanza de técnicas propias de los artesanos, los segundos, de los aspectos creativos propios de los artistas.

La primera parte de la Bauhaus se ve marcada por el profesor Johannes Itten, maestro en el curso preliminar y desarrollador de talleres de creación. Itten pretendía que en el curso inicial el aprendiz se despoje de preconceptos academicistas transformando sus conocimientos a una hoja en blanco donde imprimir la nueva capacidad creativa. Definía su proceder con afirmaciones como:

Todos los seres vivos se revelan al Hombre a través del movimiento. Todos los seres vivos se revelan en formas, por lo tanto, todas las formas son movimiento y todo movimiento se traduce en forma. Las formas son conductos para el movimiento y el movimiento es la esencia de la forma ${ }^{6}$ [Figura 4].

Y también reflexiones evocadas en los sentidos. Escribió: “Tengo un cardo delante de mí. Mis nervios motores experimentan un movimiento lacerado y espasmódico. Mis sentidos, tacto y vista, registran la nitidez de su movimiento de forma y mi espíritu ve su esencia. Experimento un cardo"7 (Droste, 2019, p. 54) [Figura 5].

Bajo estos supuestos, los ejercicios de los estudiantes, con el afán de liberar sus impulsos creativos, experimentaban con materiales, colores, texturas. Tenían resultados como el "Estudio de contrastes" del aprendiz Moses Mirkin. En el catálogo Bauhaus se describe como un ejercicio para estudiar similitudes en expresión usando diferentes significados de expresión simultáneamente. Efecto de contrastes combinados, contraste de materiales -madera, vidrio, metal-, contraste de formas expresivas -suaves, rugosas-, contraste rítmico (Droste, 2019, p. 50) [Figura 6]. 

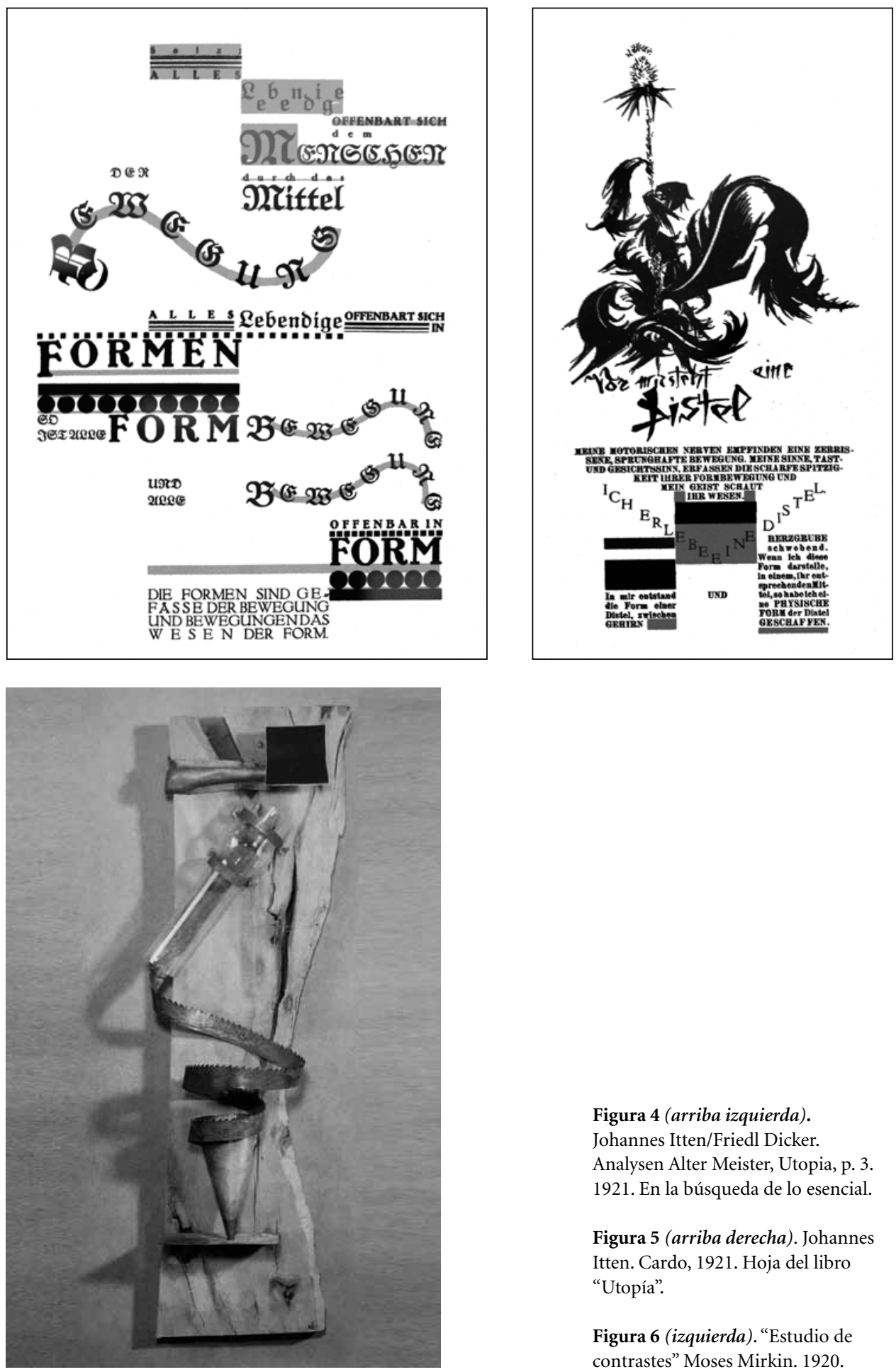

Figura 4 (arriba izquierda).

Johannes Itten/Friedl Dicker.

Analysen Alter Meister, Utopia, p. 3.

1921. En la búsqueda de lo esencial.

Figura 5 (arriba derecha). Johannes Itten. Cardo, 1921. Hoja del libro "Utopía".

Figura 6 (izquierda). "Estudio de contrastes” Moses Mirkin. 1920. 


\section{De Stijlse toma Bauhaus ${ }^{8}$}

En 1922 comienzan a evaluarse las ideas. Cayeron en la cuenta de que se habían desviado de sus propósitos originales. Se ha de recordar que el expresionismo no era sino un síntoma de la crisis que estaba atravesando la sociedad en el primer cuarto del siglo XX

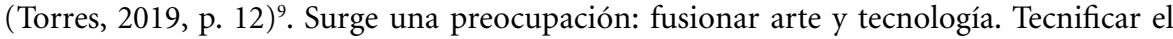
arte suponía un manifiesto sólido que diese por terminado aquel jam expresionista de los años precedentes.

El Manifiesto de De Stjl fue justamente una vuelta a lo básico y la piedra de una nueva forma disciplinar para los talleres de creación. La noción de forma era de hecho totalmente opuesta a la que manifestaba Itten. Se recurría a los elementos básicos, que eran únicos e indiscutibles: línea recta, plano -es decir, la ortogonalidad-, colores básicos. Estos elementos se organizaban en un universo axonométrico ilimitado donde los elementos generaban un espacio en libertad. Piet Mondrian y Theo Van Doesburg, los fundadores de De Stijl, estaban de acuerdo en aquello o por lo menos al principio hasta que Van Doesburg introduce la diagonal y las posiciones entre ellos se alejan.

Una conversación de dos de los fundadores del Movimiento De Stijl, Theo Van Doesburg y Vilmos Huszár muestra una clara preocupación porque se asuma la disciplinaridad de los talleres: "Todos hacen lo que sienten en ese momento, lejos de cualquier disciplina estricta ¿Dónde está el intento de crear una obra de arte unificada, una configuración unificada de espacio, forma, color" (Droste, 2019, p. 108). Otra muestra de la disparidad en los criterios de enseñanza entre Itten y van Doesburg aparece en la revista Mécano, en 1922 [Figura 7]. Una caricatura de la autoría de Peter Röhl ${ }^{10}$ muestra dos hombres mirándose de frente; el de la derecha es el "hombre natural" agarrando un cardo, el segundo, el "hombre construido". Representa al sensible expresionista Johannes Itten y el objeto frecuente en sus clases y la contraposición de Van Doesburg que cuando vino a enseñar en la Escuela Bauhaus la reprobó como un "atasco expresionista" sin ninguna disciplina.

Los alumnos desarrollaban sus prácticas con plena conciencia de tal disparidad. Werner Graeff, estudiante de la Bauhaus comentó sobre Itten y Doesburg:

Mientras uno empujaba hacia la individualidad, el segundo interesaba lo constructivo. Uno abogaba por una paleta de colores individual, el otro junto a Mondrian insistía en una paleta universal: los colores primarios. De igual manera, cuando se trataba de la tipografía (Droste, 2019, p. 114).

A los nuevos talleres encaminados a través de los principios disciplinares de De Stijl ha de sumarse la presencia de Moholy-Nagy. Sus intenciones se encaminaron a resolver los problemas prácticos del diseño insistiendo en el buen uso de la técnica y los materiales. El rastro expresionista parecía extinto, la educación se enfocaba en el conocimiento y control de los materiales y las máquinas. Moholy quería que los "Maestros Artesanos sean activos en una escala mayor y más viva para cuando las personas dejen los talleres tengan mejores y más amplias habilidades a través del empleo deliberado de las máquinas" (Droste, 2019, p. 128). 


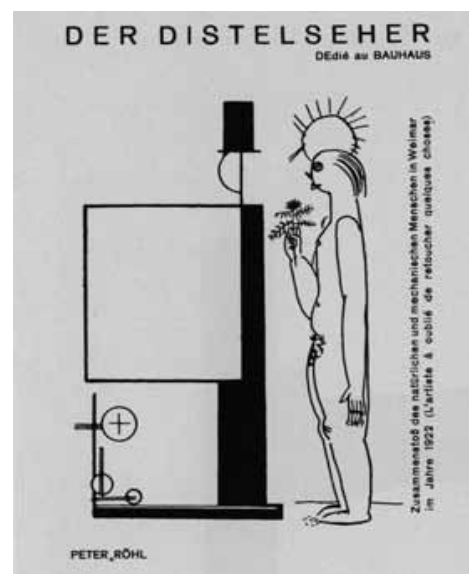

Figura 7 (arriba). The Thistle-Seer. Karl Peter Röhl. 1922.

Figura 8 (derecha). The Thistle-Seer. Karl Peter Röhl. 1922.

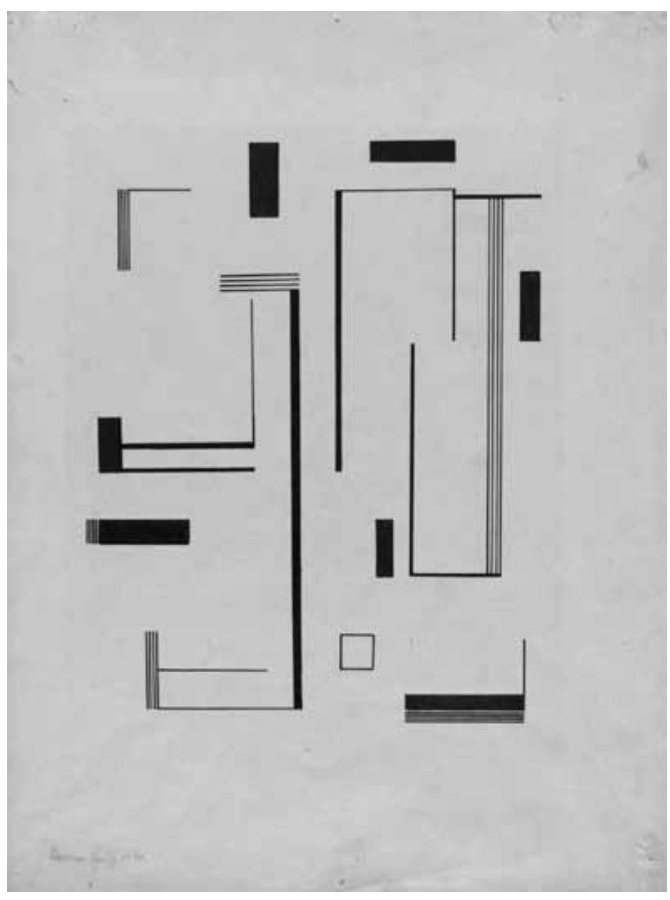

\section{Arte y tecnología en el espacio doméstico}

La insignia "arte y artesanía, una nueva unidad" promulgada desde 1919 pasó a ser "arte y tecnología, una nueva unidad", en 1922. Walter Gropius intentaba desde el inicio que la Escuela sea productiva, un factor que la distinguía de otras. Los alumnos -aprendices- podrían alcanzar ese fin pues recibían dos años de entrenamiento artístico y artesanal y luego de aprobar su examen final podrían volverse empleados y ser pagados como jornaleros.

Pero, quizá detrás de esta nueva orientación hacia el diseño de objetos prototípicos estaba el aspecto financiero. Con el fin de que la Escuela pudiese independizarse de los subsidios estatales propuso incluir talleres de producción a los ya existentes talleres de diseño.

Pronto aparecieron presiones políticas y financieras que reclamaban una muestra del trabajo que se estaba realizando en la Escuela. Así se dio paso a la primera Exposición de la Bauhaus en 1923.

La muestra, de un éxito inesperado, reunió a un público diverso, desde personalidades de la industria miembros del Werkbund hasta políticos, senadores y arquitectos como Mies van der Rohe o Max y Bruno Taut. El contenido de la exposición se basaba en los produc- 


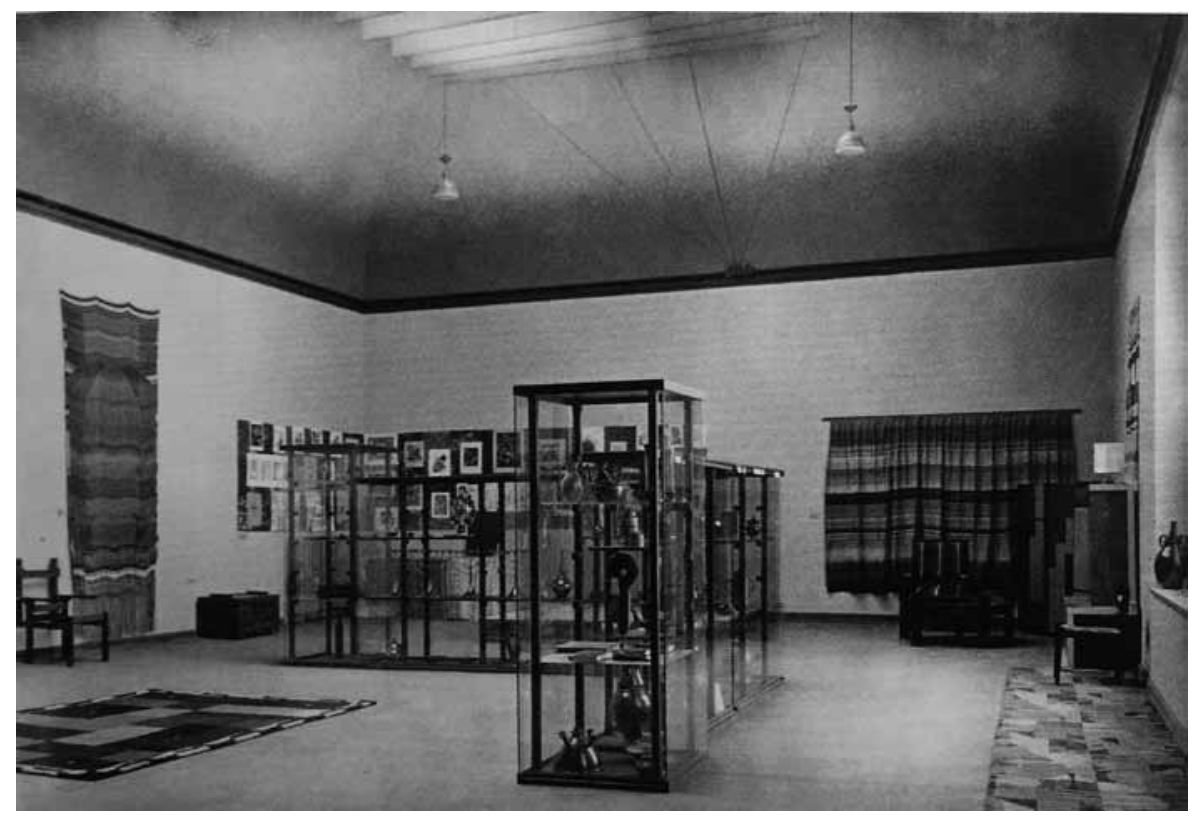

Figura 9. Exposición Bauhaus en el último piso de su sede. A la izquierda se ve el mueble wood-statchair de Marcel Breuer. Hacia la derecha, la silla revestida de tela coloreada, también de Breuer en colaboración con Gunta Stölz.

tos de los talleres, murales, frescos y selección de obras de los maestros. Pero la pretendida "unidad" -arte y tecnología- no era fácilmente apreciable, ni tampoco la importancia que se le concedía a la tecnología (Torres, 2017, p. 25).

En el apartado para arquitectura, la Exposición Internacional de Arquitectura organizada por Gropius en el marco de la Exposición Bauhaus, se expusieron maquetas y dibujos, todos ellos de línea funcional y a la vez de dinámica arquitectura. Sin embargo, la casa experimental Am Horn, diseñada en 1922 por el pintor Georg Muche, es con diferencia el ejemplo que evidenció el intento de la industrialización, la lógica funcional y una nueva forma de plantear el espacio doméstico. Representa en este caso la unificación del diseño de mobiliario interior, utilería doméstica y espacio arquitectónico.

Pero también simboliza el primer ejemplo práctico de la nueva vida -la vida moderna- en Alemania. La planta arquitectónica resultaba una innovación a la época: sin corredores, con los cuartos distribuidos alrededor de un salón, baños accesibles directamente desde los dormitorios. La cocina diseñada explícitamente para su propósito con muebles de Marcel Breuer y un salón comedor grande suficiente para contener una mesa y 6 a 8 sillas. El espacio abierto hacía posible mirar a los habitantes desde el área de cocina, por ejemplo. 


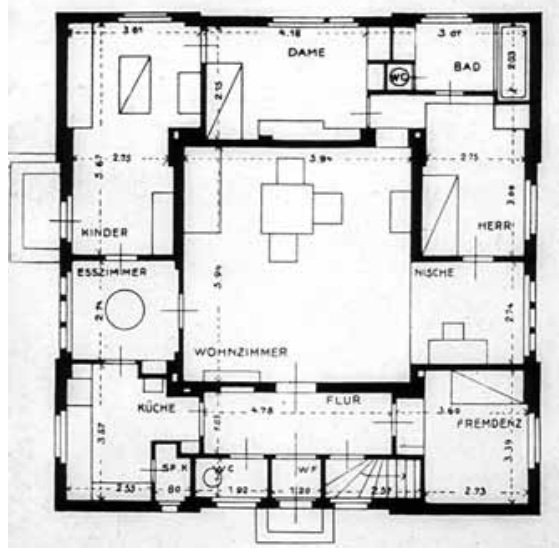

Figura 10 (izquierda). Planta

de la Casa Am Horn.

Figura 11 (abajo). La

Exposición Internacional de Arquitectura organizada por Gropius en el marco de la Exposición Bauhaus 1923. Se aprecian el plano de la Bauhaus, maquetas de unidades de vivienda modulares off-the-peghouses y hacia la derecha, fotografías de edificios de Erich Mendelson y Erwin Gutkind.

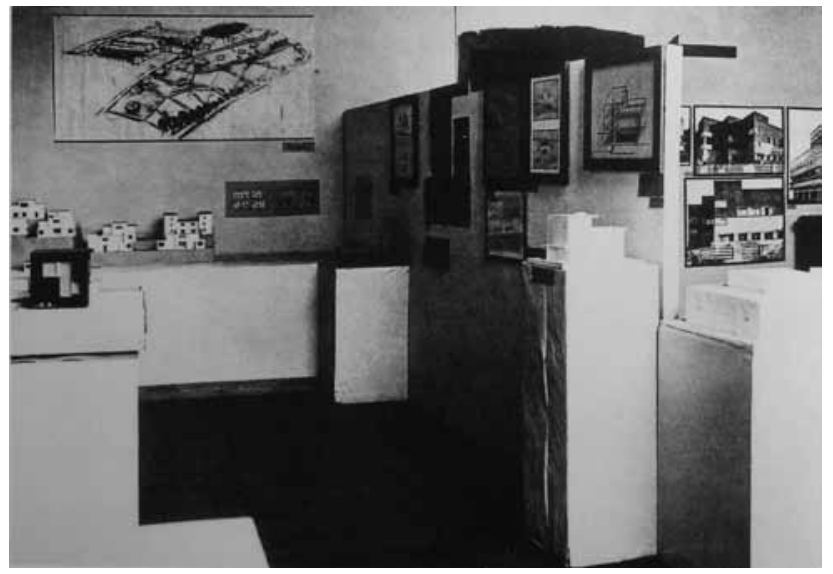

No sorprende tanto que a través de la arquitectura se haya puesto en escena la clara intención de la normalización, de la industrialización en el diseño y en el espacio. Si recordamos la arquitectura residencial europea de inicios de s. XX podríamos intuir que el camino estaba direccionado como respuesta que el Movimiento Moderno planteó al encontrarse con una ciudad sometida a las dinámicas de la industrialización. En efecto, los arquitectos modernos llevaron investigaciones enfocadas en el estudio de las relaciones interdependientes entre célula habitable y forma urbana. Para Le Corbusier por ejemplo, en sus primeras formulaciones urbanísticas, el punto de partida no es la utopía urbana-como 
generalmente se piensa- sino el estudio sesudo de la casa del hombre en la ciudad moderna. La versión de 1922 de los Immeubles-Villas es ejemplar en este sentido. Le Corbusier organiza los bloques de edificios en hilera, paralelos y comunicados por dos núcleos para la circulación vertical con escaleras, ascensores y puentes. Los corredores dobles dividen la circulación de "servicio" de la "pública". Es a fin de cuentas un gran edificio de 150x55 metros aproximadamente resuelto con la noción de conjunto habitacional que ha absorbido la calle y alude a una manzana vertical. Probablemente el edificio fue propuesto en un lugar concreto de París que determinaría sus proporciones y su disposición general pues en la posteridad el proyecto fue re-editado con importantes cambios para integrarse al proyecto de la Ville Contemporaine ${ }^{11}$. El proyecto de los Immeubles-Villas es un estudio profundo de Le Corbusier sobre el ideal de armonía entre la vida individual y colectiva. La organización funcional como vivienda y como edificio dan cuenta de la negación hacia el modelo de vivienda ochocentista paleada además por el proceso de concentración industrial. La vivienda se resuelve en un espacio rectangular de $15 \times 12 \mathrm{~m}$ aproximadamente incluyendo, por supuesto, los vacíos definidos para las terrazas.

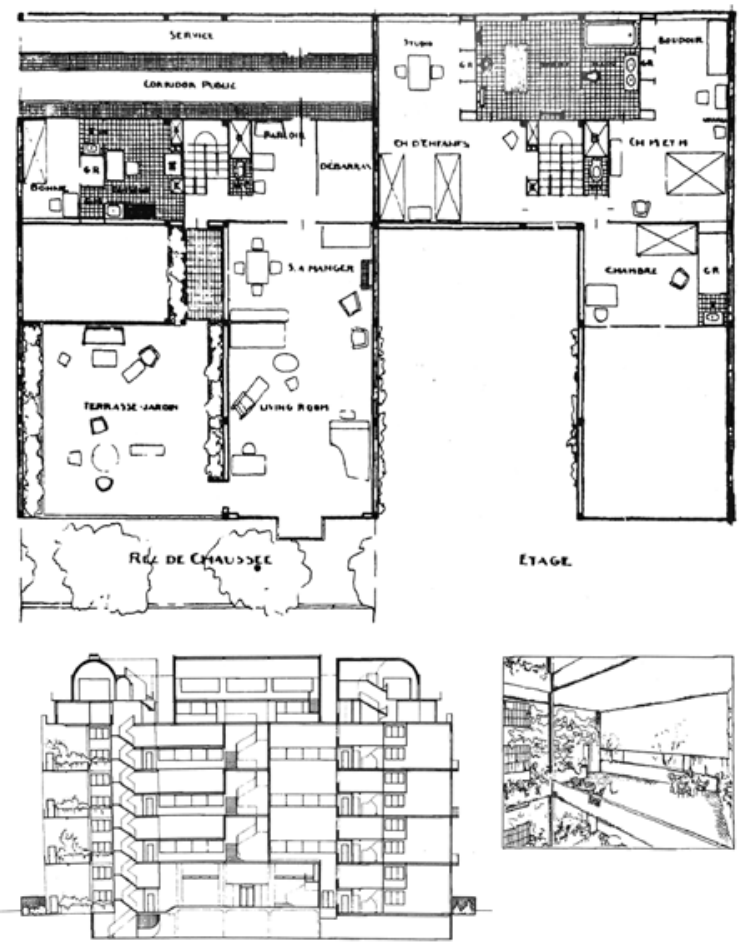

Figura 12. ImmeubleVillas, versión de 1922. 

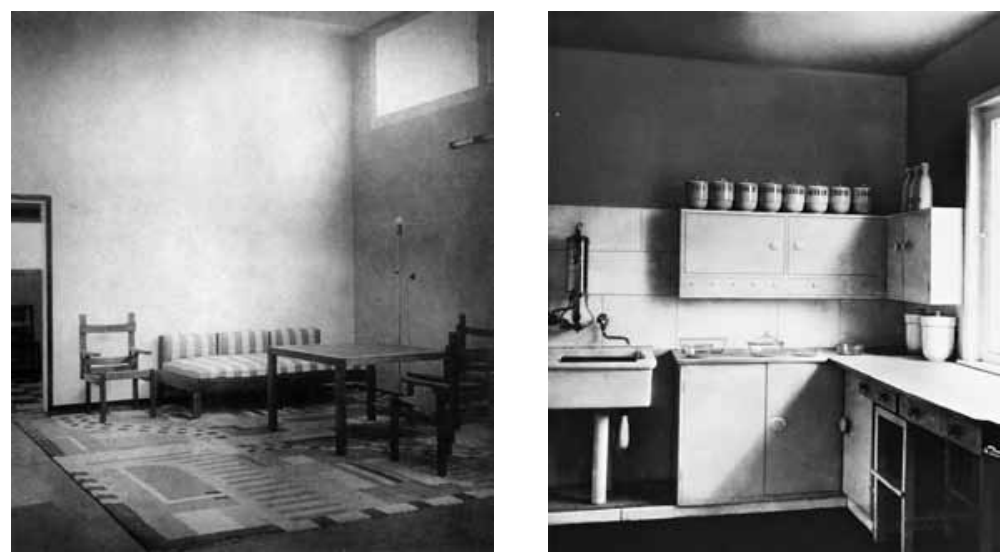

Figura 13 (izquierda). Salón de la Casa Am Horn. 1923. Figura 14 (derecha). Cocina de la Casa Am Horn. 1923

El pensamiento y acción hacia una nueva forma de vivir tiene especial interés en la casa Am Horn porque detona la sensibilidad del uso del espacio doméstico, cosa que hoy por hoy podría mirarse como mero complemento del espacio construido y previamente determinado por su función. Esta sensibilidad espacial se evidencia en todas las estancias de la casa: el salón acondicionado con los muebles de Marcel Breuer y la alfombra de Martha Erps [Figura 13] o la cocina-que luce práctica aún a nuestros días- fue diseñada por Benita Koch-Otte y Ernst Gebhardt, los contenedores sobre los estantes y los cuencos de vidrio jenaglass resistentes al horno son de Theodor Bogler [Figura 14].

La cocina fue el primer espacio moderno de su tipo. Un diseño riguroso que involucró ergonomía y sobretodo utilidad en cuanto a la "economía del gesto". Espacios de trabajo a lo largo de las ventanas, sillas que cabían bajo los mesones y economizaban espacio; superficies lisas y fáciles de limpiar. Los electrodomésticos de "ultima tecnología" -el hervidor de agua y la lavadora en el mueble- fueron esenciales en el diseño de los mobiliarios que demostraron el valor de los avances tecnológicos.

La novedad era tal que la crítica no encontró otro caso similar para compararla, salvo las salas de operación hospitalarias o sitios de equipamiento técnico: "Altas lámparas estándar de tubos de hierro y vidrio, varias, sin reflejos de sombras de seda, recuerdan instrumentos de física; los asientos parecen telares, los muebles recuerdan las imprentas, las teteras, los medidores de agua" (Giedion, 1924).

Es de suponer que la fuerza de su significado trascendió hacia proyectos futuros, muy próximos, por ejemplo en la serie de 7 casas diseñadas por Walter Gropius y Lázló Moholy-Nagy para los profesores de la Bauhaus en Dessau [Figuras 15-16]. 


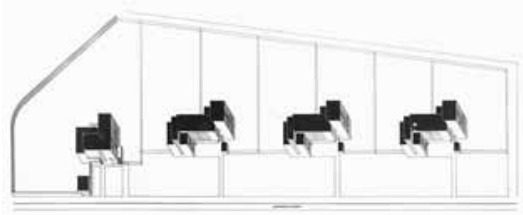

Figura 15 (arriba). Casas de los Maestros en Dessau. Isometría del emplazamiento, 1925 c. Desde la izquierda: Casa Gropius, Casa Moholy-Nagy/Feninger, Casa Muche/ Schlemmer, Casa Kandinsky/Klee.

Figura 16 (derecha). Casa de Walter Gropius. Casa de los Maestros en Dessau, 1927. Fotografía de Lucía Moholy-Nagy.

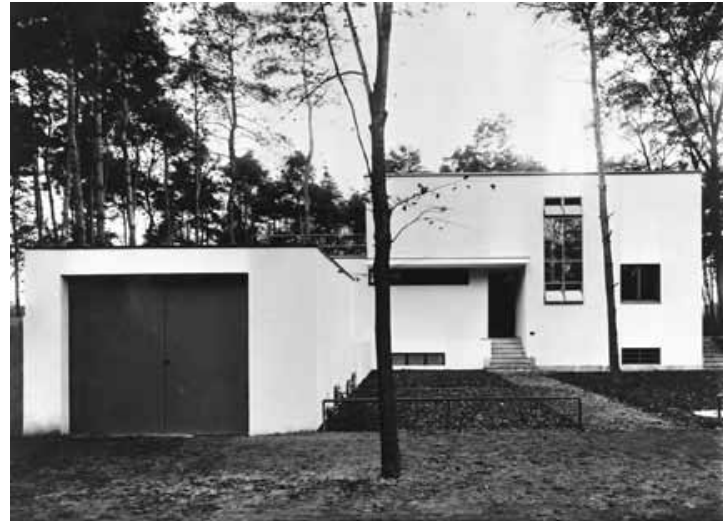

El proyecto consistía en una casa para el Director y tres casas pareadas, giradas a noventa grados, para los docentes. El ejercicio representaba un manifiesto del pensamiento arquitectónico y estético pues la oportunidad de dar cabida al directorio docente de la Escuela ofrecía llevar a cabo una ejemplificación de un nuevo -y quizá, muy costoso- estilo de vida. Las casas recogen el ejercicio large-scalebuilding set ${ }^{12}$ desarrollado por Gropius en 1922, junto a los modelos off-the-peg e incluyen mobiliario exclusivo de Marcel Breuer y ambientaciones de los espacios con colores propuestos por Paul Klee y Wassily Kandisky. Los armarios se mostraban abiertos a la circulación al igual que una serie de estanterías y accesorios de utilería integrados, como tablas de planchar, mesones plegables, sofás convertibles.

Cada inquilino modificó los colores de los muros interiores según su juicio. Nina Kandinsky concluía que cada ambiente de su casa era un "todo arquitectónico" luego de describir la composición de los colores de los espacios: el estudio amarillo pálido de su esposo Wassily o el rosa claro en el salón con un nicho en pan de oro.

Las viviendas distaban de la concepción estándar de la época por la evidente inusual concepción espacial de la función y por el lujo con el que la resolvían. Schlemmer escribió a su mujer "Cuando he visto las casas, me he asustado y he tenido la impresión que algún día vendrán aquí, delante de ellas, personas sin techo, mientras que los señores artistas toman baños de sol sobre la terraza de sus propias casas" (Torres, 2017, p. 55). Y, Klee al fin de un tiempo se quejó de los altos valores de pago de la calefacción. Gropius lo sabía todo aquello pero también se atrevía a presagiar que los lujos de la época serán tomados como una normalidad en un futuro próximo. 

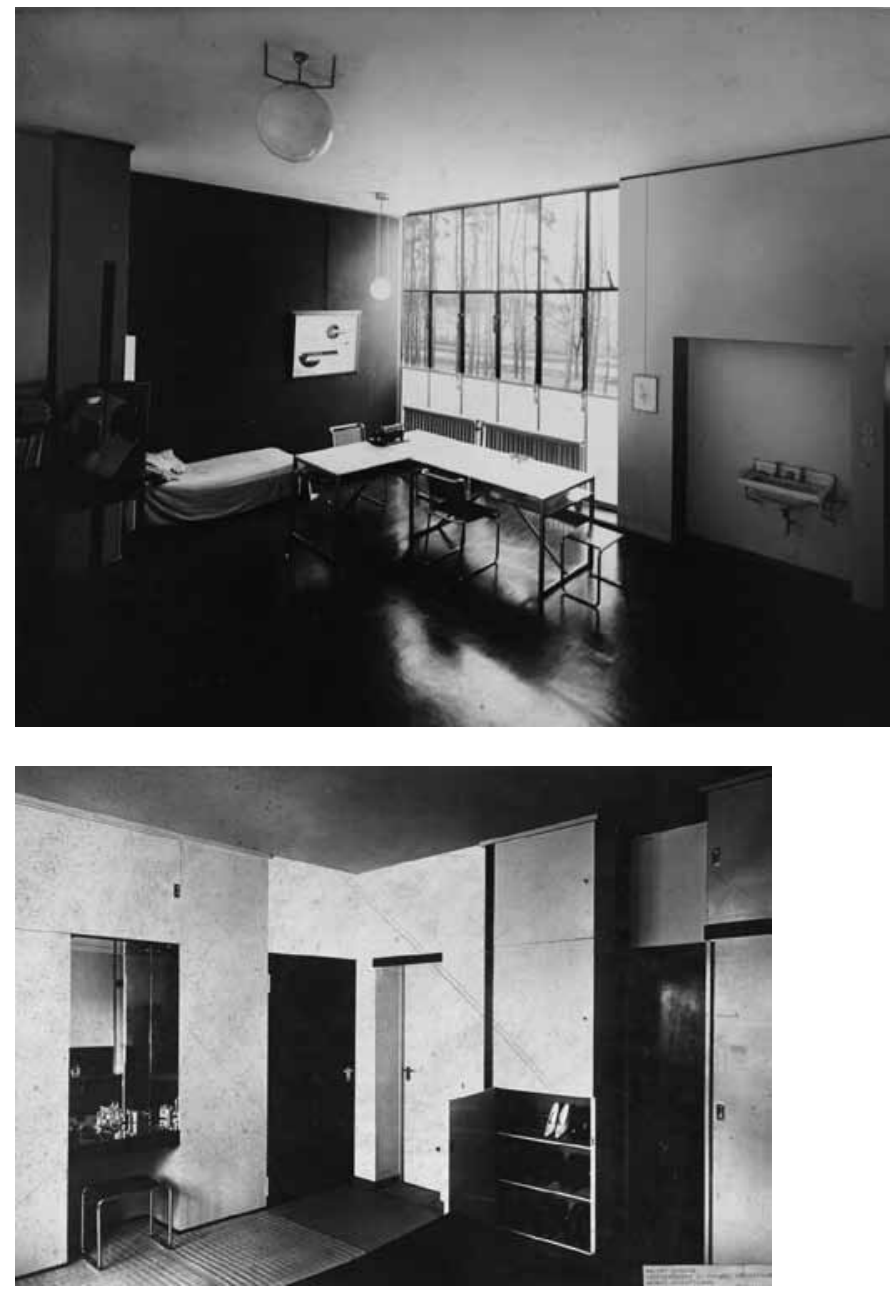

Figura 17 (arriba). Estudio de la Casa de Moholy-Nagy. Casa de los Maestros en Dessau, 1927. Fotografía de Lucía Moholy-Nagy.

Figura 18 (izquierda). Casa de Walter Gropius, vista del dormitorio. Casa de los Maestros en Dessau, 1927. Fotografía de Lucía Moholy-Nagy.

La mirada hacia la arquitectura no será lo suficiente fuerte sino hasta el traslado de la sede de la Escuela a Dessau. Allí pasa a ser un instituto del talle de una escuela técnica superior. El departamento de arquitectura se crea en 1926 bajo la dirección de Hannes Meyer quien modificará el programa sometiendo a éste lo referido a construcción y equipamiento interior e incrementando en los años sucesivos el interés hacia temas arquitectónicos y urbanos. 


\section{La persistencia de una idea: evolución de la noción del espacio doméstico}

Hacia 1933 se cierra la Escuela producto de una serie de sucesos acarreados desde el traslado de la sede a Dessau. Sin embargo no fue motivo para dejar de lado el proceso hacia un nuevo uso del espacio arquitectónico. La semilla había germinado y dado los tiempos convulsos que transcurrían se necesitaba continuar la reflexión sobre qué tipo de vivienda conviene construirse en cada momento, cuál su programa y su distribución. Se dirigía hacia el análisis de una vivienda con espacios definidos y a la vez compartidos.

En varios casos a nivel mundial, esta reflexión sobre el espacio doméstico, resultaba una mirada hacia el pasado, hacia la supuesta superación de la habitación única, tipo "multifunción" de la tipología de vivienda decimonónica que diferenciaba -y dividía- claramente las zonas del habitar debido a preocupaciones higienistas [Figura 19]. Se ha de recordar que la cocina de la segunda mitad del siglo XIX es una cocina flexible, determinada solo por la disposición del lavadero y el fogón. El resto se construye a voluntad y en función de la disponibilidad del espacio y el dinero (Segura, 2017, p. 30).

Hemos visto que desde el diseño interior y los talleres en la Bauhaus se procuró la economía espacial, con ello aparecen criterios de organización de la vivienda guiados a través de la economía del gesto. En consecuencia, el espacio multifunción adopta como núcleo a la cocina y a partir de ella se racionaliza los movimientos y las estancias de vida diurna y nocturna. Haría falta que simplemente se diseñen muebles empotrados que colaboren a esta adaptación.

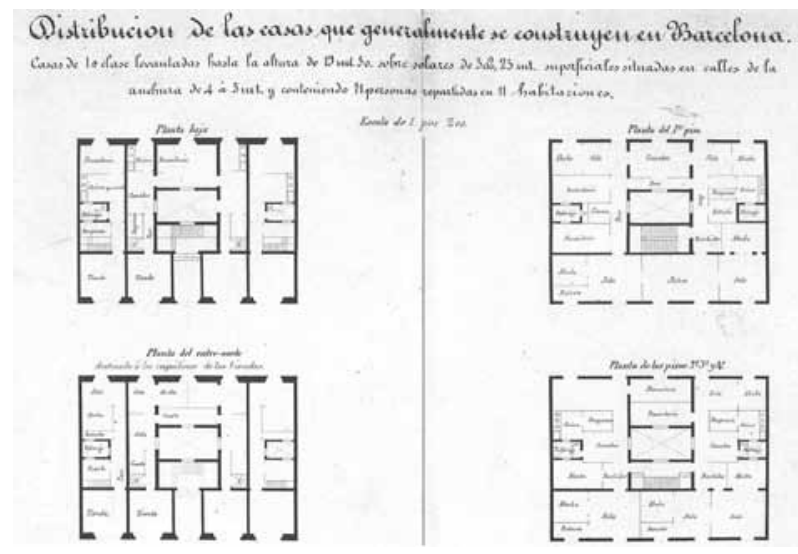

Figura 19. Viviendas de Barcelona inicio s.XIX. 
Es necesario mencionar que las dinámicas del uso de los espacios son interferidas por prácticas culturales que bien sabemos, varían de acuerdo a múltiples factores. Por mencionar un ejemplo europeo, el caso de la vivienda moderna en Barcelona y enfocando al episodio de vivienda masiva entre 1930 y 1960 se puede ver que en aquellos años, la importancia de la cocina como centro del único espacio versátil es contradictorio al comportamiento que ha tenido en la historia de Barcelona.

La cocina en la casa rural decimonónica compartía el espacio del comedor, luego, la cocina pasó a estar siempre oculta y con fuertes deficiencias higienistas. La modernidad propuesta en 1859 por Ildefons Cerdà reflexionaba sobre la importancia de la buena ventilación y asoleamiento de todos los espacios, sobre todo, de la cocina y los baños. Sin embargo no será sino hasta el desarrollo de la vivienda masiva cien años después que vendrá la revisión de la cocina hacia un modelo de espacio de trabajo que se asocia al estar y al ocio.

El proyecto del Polígono del Sud-Oeste del Besós ${ }^{13}$ en el levante barcelonés es un ejemplo de vivienda masiva de los años cincuenta. Es único por su extensión, por ubicarse en la periferia y por su capacidad de adherirse a la trama urbana de manzanas Cerdá ${ }^{14}$ aunque en el momento del diseño y construcción la zona no se encontraba consolidada. El proyecto del Polígono ${ }^{15}$ parte de un Plan Parcial que a pesar de haberse modificado guardó gran parte de su esquema inicial. En el Plan se asume plenamente el bloque exento desvinculado de la trama viaria y de la geometría de la manzana Cerdá y resuelve el emplazamiento de los bloques de tal manera que deja libres a las alineaciones viarias horizontales. Para la propuesta de ordenación urbana se toma al bloque de vivienda como la unidad constructiva del sistema de habitación.

De la complejidad de este proyecto se extrae particularmente un edificio, el primer tipo de bloque de viviendas: "Bloque A". El bloque contiene doce viviendas por planta, cada una se distribuye en una única crujía de 4,5 metros de luz, entre paredes de carga perpendiculares a la fachada. Un frente soleado queda abierto y se retrasa el cerramiento acristalado dando lugar a una galería. Es esta la estancia principal que alberga las funciones: estancia, comedor, cocina y un espacio para una eventual cama supletoria.

La propuesta responde al criterio de que la vivienda debe ser mínima para que esté al alcance de las economías débiles, pero generosa en adaptarse a las prioridades específicas de cada familia. El resto de la vivienda se reduce a un aseo y a dos dormitorios mínimos, uno de una cama de matrimonio y otro de dos camas individuales. La precariedad económica no es excusa suficiente para evitar alcanzar la calidad espacial. En estos bloques de vivienda de bajo costo, el acero es un insumo de alto valor, por tanto se utiliza justo donde resulta insustituible: para soportar las tracciones. Y a la vez conforma las mamparas de la terraza y con ello la modulación del espacio interior. 

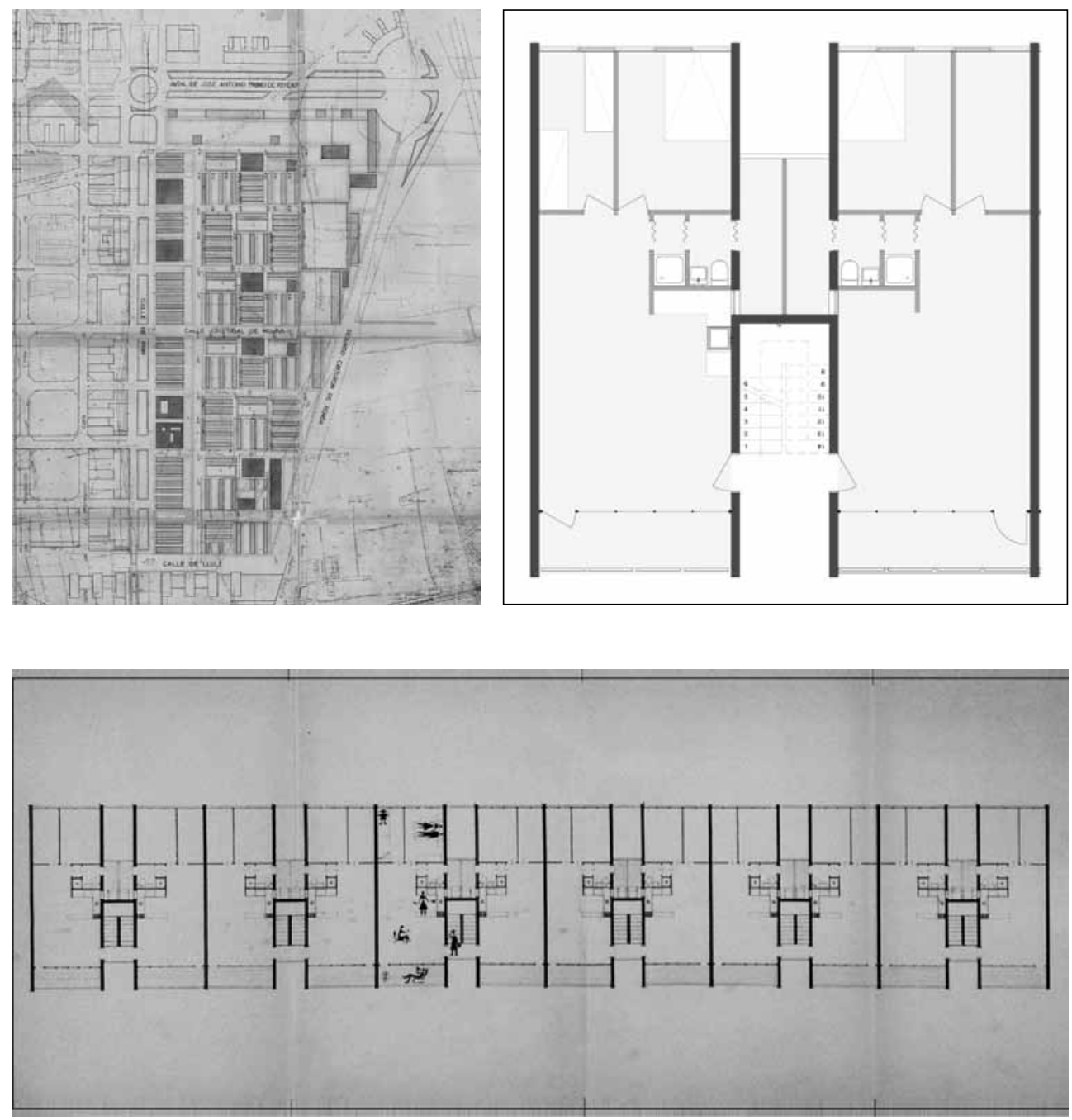

Figura 20 (arriba izquierda). Plan Parcial del Polígono del Sud-Oeste del Besós con la ubicación del Bloque A. 1959. Figura 21 (abajo). Bloque A. Polígono del Sud-Oeste del Besós. 1959. Figura 22 (arriba derecha). Vivienda tipo del Bloque A. 


\section{Observaciones finales}

Resulta evidente que la economía del gesto será influyente en el diseño interior modular, provocando alto nivel de eficiencia. La modernidad arquitectónica tiene en este sentido un enlace directo hacia el proceso de construcción de espacio que cobró fuerza en la escuela de la Bauhaus. La optimización máxima del espacio en la vivienda y versatilidad de uso como objetivo, denota la preocupación por la adaptabilidad de la vivienda en el futuro. La posibilidad para ello es sin duda la modulación derivada a su vez de la solución arquitectónica del espacio. En este sentido, el rigor en la modulación al contrario de ser una restricción, provoca una fundamental libertad de acción. Se posibilitaría además que se genere un sistema que pueda extrapolarse al espacio urbano: la dinámica de articulación entre llenos y vacíos que resulta justamente de un proceso de modulación riguroso y de control de las dimensiones.

A este punto puede llegar a afirmarse que la verdadera experiencia de la Escuela se retrata en sus alumnos y en los arquitectos quienes a pesar de no haber pasado la Escuela ejercieron la arquitectura a través de su influencia. Ellos y sus obras son quizá los verdaderos protagonistas y quienes dan cuenta de que más allá de la Institución, los ideales persistieron en el espíritu del arte total unido a la arquitectura. El diseño del espacio habitable quizá no podría haberse palpado si no fuese a través de ciertas personalidades que la historia se ha olvidado destacar.

Eileen Gray por ejemplo fue una de las personas más sensibles y más innovadoras en el campo del "diseño total del espacio", es decir en la composición que incluye el mobiliario, la luz, las texturas, los colores, los tejidos. Igualmente Benita Koch-Otte que si bien destacó principalmente con sus elaborados diseños textiles, su aporte a la casa Am Horn fue determinante en la reflexión sobre la funcionalidad y estética de la cocina moderna. Ambas emprendieron un campo en el que los arquitectos del Movimiento Moderno apenas habían explorado.

\section{Notas}

1. Arbeitsratfür Kunst, traducido como Comité de Trabajo para el Arte fundado en 1918. 2. A pesar de los intentos de varias ciudades por abrirse hacia la Era Moderna logrando planes urbanos de extensión donde la vivienda y la industria podrían convivir, el impacto de la industrialización fue tal que superó con creces toda previsión planteada. Un caso: El Plan de Ensanche de Barcelona de Ildefons Cerdà en 1859 a más de plantear la extensión de la ciudad con el sesudo modelo morfológico de las manzanas, propuso que las grandes industrias se ubiquen cerca de los ríos Besós y Llobregat mientras que las pequeñas y medianas serían distribuidas a lo largo de la ciudad. Pero la dinámica industrial desarrolló desequilibrios, sobretodo en el barrio de Poblenou y la zona de Levante.

3. Heinrich Petre Tessenow. (1876 Rostock - 1950 Berlín). Más información sobre su biografía y obra en: Muriel, Emanuel. (1980). Contemporary Architects. Lóndres: PalgraveMacmillan UK. 
4. Otras Escuelas relevantes, además de las mencionadas, fueron la Escuela de Arte de La Chaux de Fonds, donde se formó Le Corbusier; Wienner Werkstätte, fundada en Viena en 1903 o la Colonia de Artistas de Darmstadt, fundada en 1899.

5. Walter Gropius en el Manifiesto Bauhaus 1919.

6. En Analysen Alter Meister, Itten proponía la importancia de buscar las formas esenciales, los movimientos naturales que tienen y resultan de los objetos. La frase descrita es la traducción del cartel desde una versión en inglés.

7. El cardo fue un objeto frecuente en las clases de Itten. Su particular forma era adecuada para sus propósitos educativos.

8. La expresión se apoya, además de la explicación que le procede, en una postal que Theo Van Doesburg envía a su amigo Antony Kok, en septiembre de 1921. La foto postal muestra al edificio sede de Bauhaus en Weimar con sus muros pintarrajeados con las palabras "De Stijl". Para ser aún más exhaustiva la idea, el dibujo de un sol en la esquina superior derecha también contiene el texto "De Stijl".

9. Jorge Torres Cueco sugiere considerar la imprecisión del término "expresionismo". Advierte que el término se refiere por un lado, a la capacidad de los artistas y las obras de arte para expresar emociones, sentimientos y estados de ánimo; por otro, alude a un grupo de artistas con unos códigos formales imprecisos - uso de composiciones complejas, formas fluidas o angulosas, colores vivos y contrastantes- que desarrollaron su producción aproximadamente entre 1910 y 1925 en Centroeuropa. En: Torres, J. (2017). Bauhaus. El mito de la modernidad. Arquia documental 35. Barcelona, España: Fundación Arquia, p. 11.

10. Peter Röhl fue estudiante de la Bauhaus y autor de la primera insignia de la Escuela.

11. La Ville Contemporaine fue un proyecto utópico de una ciudad de tres millones de habitantes diseñada por Le Corbusier en 1922 para el centro de París. En el centro dispone 24 rascacielos cruciformes - principalmente- de 190x190m y más de 200m de altura para comercio y hotelería. Alrededor de ellos los barrios residenciales se disponen en bloques donde cada vivienda tiene un espacio exterior, cada una es una casa por sus propios medios.

12. Es un sistema de composición conformado de seis tipos de células espaciales que pueden combinarse de varias maneras hasta formar una "arquitectura-panal".

13. Fue el segundo Polígono de vivienda promovido por el Patronato Municipal de Vivienda de Barcelona. Su extensión de casi 40 hectáreas le posiciona como el proyecto de vivienda de mayor dimensión en la historia de la vivienda masiva de Barcelona. Sus proyectistas principales fueron Guillermo Giráldez, Pedro López Íñigo y Javier Subías.

14. La manzana Cerdá se refiere a la unidad de configuración urbana del Plan de Ensanche diseñado por Ildefons Cerdá en 1859.

15. Término acuñado a los proyectos de extensa dimensión. De ahí las expresiones: polígono de vivienda, polígono industrial.

\section{Bibliografía}

Aguirre, F. (2018). La obra residencial de Giráldez, López y Subías desde el Polígono del SudOeste del Besós. (Tesis Doctoral) UPC-ETSAB, Barcelona, España. 
Cerdá, I. (1859). Teoría de la construcción de las ciudades aplicada al proyecto de reforma y ensanche de Barcelona.

Cortes, J. A. (2016). Aleksandr Ródchenko: fotografías de arquitectura y ciudad. Click 2. Barcelona, España: Iniciativa Digital Politécnica.

Curtis, J. R. W. (2012). La arquitectura moderna desde 1900. Nueva York, USA: Phaidon.

Droste, M. (2019). Bauhaus 1919-1933. Berlín, Alemania: Taschen.

Frampton, K. (1999). Historia Crítica de la arquitectura moderna. Barcelona: Editorial GG.

García, J. M. (2002). Heinrich Tessenow Pensamiento utópico, germanidad, arquitectura. Valldolid, España: Secretariado de Publicaciones Universidad de Valladolid.

Martí, C. (Ed.) (1991). Las formas de la residencia en la ciudad moderna, Vivienda y Ciudad en la Europa de entreguerras. Barcelona, España: Edicions UPC.

Muriel, E. (1980). Contemporary Architects. Lóndres: Palgrave Macmillan UK.

Ravetllat, P. J. (2014). Habitatgeiciutat. Des delsedificis. Barcelona, España: Iniciativa Digital Politécnica.

Ródchenko. (2001). Geometrías [cat. expo., Fundación Juan March, Madrid]. Madrid, España: Fundación Juan March.

Segura, I. (2017). Cuines de Barcelona. El Laboratori domèstic de la ciutat moderna. Barcelona, España: Comanegra.

Torres, J. (2017). Bauhaus. El mito de la modernidad. Arquia documental 35. Barcelona, España: Fundación Arquia.

Pévsner, N. (1963). Pioneros del Diseño Moderno de William Morris a Walter Gropius. Buenos Aires, Argentina: Ediciones Infinito.

\section{Imágenes}

Imagen 1. Fire scape, 1925. AA.VV. Ródchenko: la construcción del futuro. (2009). Barcelona: Varis.

Imagen 2. Balcones de la serie "El edifico de la calle Miasnitskaia", 1925. AA.VV. Ródchenko: la construcción del futuro. (2009). Barcelona: Varis.

Imagen 3. Vivienda para un trabajador. Heinrich Tessenow, 1908. MARTÍ, Carles. (Ed.) (1991) Las formas de la residencia en la ciudad moderna, Vivienda y Ciudad en la Europa de entreguerras. Barcelona, España: Edicions UPC, p. 22.

Imagen 4. Johannes Itten/Friedl Dicker. Analysen Alter Meister, Utopia, p. 3. 1921. En la búsqueda de lo esencial. DROSTE, Magdalena. (2019). Bauhaus 1919-1933. Berlín, Alemania: Taschen, p. 49.

Imagen 5. Johannes Itten. Cardo, 1921. Hoja del libro "Utopía”. DROSTE, Magdalena. (2019). Bauhaus 1919-1933. Berlín, Alemania: Taschen, p. 55

Imagen 6. "Estudio de contrastes" Moses Mirkin. 1920. DROSTE, Magdalena. (2019). Bauhaus 1919-1933. Berlín, Alemania: Taschen, p. 51.

Imagen 7. The Thistle-Seer. Karl Peter Röhl. 1922. DROSTE, Magdalena. (2019). Bauhaus 1919-1933. Berlín, Alemania: Taschen, p. 114.

Imagen 8. Werner Graeff. Construction. 1921. MoMA’s collection (Se necesita autorización de uso). 
Imagen 9. Exposición Bauhaus en el último piso de su sede. DROSTE, Magdalena. (2019). Bauhaus 1919-1933. Berlín, Alemania: Taschen, p. 235.

Imagen 10. Planta de la Casa Am Horn. DROSTE, Magdalena. (2019). Bauhaus 1919-1933. Berlín, Alemania: Taschen, p. 229.

Imagen 11. La Exposición Internacional de Arquitectura organizada por Gropius en el marco de la Exposición Bauhaus 1923. DROSTE, Magdalena. (2019). Bauhaus 19191933. Berlín, Alemania: Taschen, p. 236.

Imagen 12. Immeuble-Villas, versión de 1922. MARTÍ, Carles. (Ed.) (1991) Las formas de la residencia en la ciudad moderna, Vivienda y Ciudad en la Europa de entreguerras. Barcelona, España: Edicions UPC, p. 63.

Imagen 13. Salón de la Casa Am Horn. 1923. DROSTE, Magdalena. (2019). Bauhaus 19191933. Berlín, Alemania: Taschen, p. 230.

Imagen 14. Cocina de la Casa Am Horn. 1923. DROSTE, Magdalena. (2019). Bauhaus 1919-1933. Berlín, Alemania: Taschen, p. 231.

Imagen 15. Casas de los Maestros en Dessau. Isometría del emplazamiento, 1925 c. DROSTE, Magdalena. (2019). Bauhaus 1919-1933. Berlín, Alemania: Taschen, p. 266.

Imagen 16. Casa de Walter Gropius. Casa de los Maestros en Dessau, 1927. Fotografía de Lucía Moholy. DROSTE, Magdalena. (2019). Bauhaus 1919-1933. Berlín, Alemania: Taschen, p. 268.

Imagen 17. Estudio de la Casa de Moholy-Nagy. Casa de los Maestros en Dessau, 1927. Fotografía de Lucía Moholy-Nagy. @ Lucia Moholy Estate/Artists Rights Society (ARS), New York/VG Bild-Kunst, Bonn. Harvard Art Museums/Busch-Reisinger Museum, Gift of Walter Gropius. (Se necesita autorización de uso).

Imagen 18. Casa de Walter Gropius, vista del dormitorio. Casa de los Maestros en Dessau, 1927. Fotografía de Lucía Moholy-Nagy ( ) Lucia Moholy Estate/Artists Rights Society (ARS), New York/VG Bild-Kunst, Bonn. Harvard Art Museums/Busch-Reisinger Museum, Gift of Walter Gropius (Se necesita autorización de uso).

Imagen 19. Viviendas de Barcelona inicio s.XIX. CERDÁ, Ildefons. (1859). Teoría de la construcción de las ciudades aplicada al proyecto de reforma y ensanche de Barcelona.

Imagen 20. Plan Parcial del Polígono del Sud-Oeste del Besós con la ubicación del Bloque A. 1959. Registre de Planejament Urbanístic de Barcelona.

Imagen 21. Bloque A. Polígono del Sud-Oeste del Besós. 1959. Patronato Municipal de Vivienda.

Imagen 22. Vivienda tipo del Bloque A. Redibujo de la autora.

Abstract: The Bauhaus is the most important -if not, the most known-School of art and design of the 20th century. But the history of the School is as complex as the personalities on its scene. Looking at its evolution shows this.

Despite the relatively short time of existence the School made important contributions in the field of design, art and architecture, while forming minds and criteria of inevitable reverberation. 
Among all his contributions, this study intends to focus on the construction of living space. Thus, the work below provides a look at the evolution of the perception around the domestic space. For this, it uses the historical thread as a base in order to establish connections between this perceptions at each moment of the School and the architectural events produced inside and outside of it. At the risk of appearing to be mere coincidences between those, either because society succumbed to obsessive industrialization and its consequent dynamics and therefore demanded a single direction of thought, or because they could be assumed as isolated facts the construction of the point of view suggested, intends to add a value: persistence. This being the inherent capacity in experimentation and in the construction -in this case- of the domestic space. An attempt will be to touch one of the dimensions of the Bauhaus where the promulgated design, art and architecture appear strongly fused: in the domestic space.

It could be seen that the process of unifying art and industry -afterwards, art and artist, art and society- started with an ideology that would evolve and would become an inherent persistence in the criterion of modern form: the total construction of space without any element left undefined, thus understanding that the scale is only one of its dimensions. At this point it can be stated that the true experience of the School is portrayed in its students and also in the architects who, despite not having gone through the School, exercised architecture through their influence. They and their works are perhaps the true protagonists and those who realize that beyond the Institution, the ideals persisted in the spirit of total art along with architecture. The design of the living space perhaps could not have been felt if it were not through its contributions.

Keywords: domestic space - living space - art and technology - art and architecture - Bauhaus housing.

Resumo: A Bauhaus é a escola de design e arte mais importante -se não, a mais conhecida- do século XX. Mas a história da escola é tão complexa quanto os seus personagens. Observar sua evolução mostra isso.

Apesar do tempo relativamente curto de existência a Escola fez importantes contribuições no campo do design, arte e arquitetura, ao passo que formou mentes e critérios de reverberação inevitável.

Entre todas as suas contribuições, esta pesquisa foca na construção do espaço habitável. Assim, o trabalho fornece uma visão da evolução do pensamento em torno do espaço doméstico. Para isso, utiliza o fio histórico como base e, por meio dele, estabelecem-se conexões entre o pensamento de cada momento da Escola e os eventos arquitetônicos produzidos dentro e fora dela. Correndo o risco de parecer meras coincidências entre as conexões, seja porque a sociedade sucumbiu à industrialização obsessiva e sua consequente dinâmica e, portanto, exigiu uma única direção do pensamento ou porque poderia ser assumido simplesmente como fatos isolados, a construção do ponto de vista sugerido aqui pretende adicionar um valor: persistência. Sendo essa a capacidade inerente a experimentação e a construção -neste caso- do espaço doméstico. Portanto, será feita uma tentativa de tocar uma das dimensões da Bauhaus, onde o promulgado design, arte e arquitetura parecem fortemente fundidos: no espaço doméstico. 
Ver-se-á então que o processo de unificação de arte e indústria -posteriormente, arte e artista, arte e sociedade- começou com uma ideologia que evoluiria e se tornaria uma persistência inerente ao critério da forma moderna: a construção total do espaço sem que nenhum elemento seja indefinido, entendendo-se que a escala é apenas uma dimensão. Nesse ponto, pode-se afirmar que a verdadeira experiência da escola é retratada em seus alunos e também nos arquitetos que, apesar de não terem passado pela Escola, exerceram a arquitetura por sua influência. Eles e suas obras são talvez os verdadeiros protagonistas e aqueles que percebem que, além da instituição, os ideais persistiram no espírito da arte total, em conjunto com a arquitetura. Talvez o projeto do espaço não pudesse ser percebido se não fosse por suas contribuições.

Palavras chave: espaço doméstico - espaço habitável - arte e tecnologia - arte e arquitetura - habitação - Bauhaus.

[Las traducciones de los abstracts fueron supervisadas por el autor de cada artículo] 